\title{
Genomic analysis of the HER2/TOP2A amplicon in breast cancer and breast cancer cell lines
}

\author{
Edurne Arriola ${ }^{1, *}$, Caterina Marchio ${ }^{1,2}$, David SP Tan ${ }^{1}$, Suzanne C Drury ${ }^{3}$, Maryou B Lambros ${ }^{1}$, Rachael Natrajan ${ }^{1}$, \\ Socorro Maria Rodriguez-Pinilla ${ }^{4}$, Alan Mackay ${ }^{1}$, Narinder Tamber ${ }^{1}$, Kerry Fenwick ${ }^{1}$, Chris Jones ${ }^{5}$, Mitch Dowsett ${ }^{3}$, \\ Alan Ashworth ${ }^{1}$ and Jorge S Reis-Filho ${ }^{1}$
}

HER2 and TOP2A are targets for the therapeutic agents trastuzumab and anthracyclines and are frequently amplified in breast cancers. The aims of this study were to provide a detailed molecular genetic analysis of the 17q12-q21 amplicon in breast cancers harbouring HER2/TOP2A co-amplification and to investigate additional recurrent co-amplifications in HER2/ TOP2A-co-amplified cancers. In total, 15 breast cancers with HER2 amplification, 10 of which also harboured TOP2A amplification, as defined by chromogenic in situ hybridisation, and 6 breast cancer cell lines known to be amplified for HER2 were subjected to high-resolution microarray-based comparative genomic hybridisation analysis. This revealed that the genomes of 12 cases were characterised by at least one localised region of clustered, relatively narrow peaks of amplification, with each cluster confined to a single chromosome arm (ie 'firestorm' pattern) and 3 cases displayed many narrow segments of duplication and deletion affecting the vast majority of chromosomes (ie 'sawtooth' pattern). The smallest region of amplification (SRA) on $17 q 12$ in the whole series extended from 34.73 to $35.48 \mathrm{Mb}$, and encompassed HER2 but not TOP2A. In HER2/TOP2A-co-amplified samples, the SRA extended from 34.73 to $36.54 \mathrm{Mb}$, spanning a region of $\sim 1.8 \mathrm{Mb}$. Apart from HER2 and TOP2A, this region encompassed four additional genes whose expression levels as defined by quantitative real-time PCR are significantly higher in HER2/TOP2A-co-amplified vs HER2-amplified breast cancers: CASC3, CDC6, RARA and SMARCE1. Of the cell lines studied, SKBR3 and UACC812 showed HER2/TOP2A co-amplification. In conclusion, this is the first detailed genome-wide characterisation of HER2/TOP2A-amplified breast cancers; cell lines were identified that can be used to model these cancers in vitro. The 17q12 amplicon is complex and harbours multiple genes that may be associated with breast cancer development and progression, and potentially exploitable as therapeutic targets.

Laboratory Investigation (2008) 88, 491-503; doi:10.1038/labinvest.2008.19; published online 10 March 2008

KEYWORDS: microarrays; molecular genetics; oncogenes; amplification; topoisomerase II alpha; c-erbB2

Oncogene addiction refers to the phenomenon in which a tight dependence on the continued activity of a specific oncogene drives tumour development and progression, even in the presence of additional tumorigenic lesions. ${ }^{1}$ Consequently, identifying and inhibiting the activity or expression of the proteins encoded by these 'addictive oncogenes' are highly attractive therapeutic strategies in human cancer. This concept has been well illustrated in the case of HER2-positive $($ HER $2+)$ breast cancer, where amplification and overexpression of the HER2 (ERBB2) oncogene in approximately $20 \%$ of breast cancers on chromosome $17 \mathrm{q} 12$ have been shown to predict clinical response and improved outcome following treatment with the humanised HER2 monoclonal antibody, trastuzumab. ${ }^{2-4}$

It has recently been proposed that the association of breast cancers harbouring HER2 amplification with response to anthracyclines $^{5-7}$ may be a direct result of the frequent coamplification of TOP $2 A,{ }^{8-10}$ which maps close to the HER2 gene. TOP $2 A$ is co-amplified with HER2 in approximately $40-50 \%$ of breast cancers, ${ }^{11,12}$ and codes for topoisomerase II $\alpha$, a key protein involved in resolving topological problems such as DNA supercoiling, encountered during DNA

\footnotetext{
The Breakthrough Breast Cancer Research Centre, Institute of Cancer Research, London, UK; ${ }^{2}$ Department of Biomedical Sciences and Human Oncology, University of Turin, Torino, Italy; ${ }^{3}$ Academic Department of Biochemistry, Royal Marsden Hospital, London, UK; ${ }^{4}$ Molecular Pathology Programme, Centro Nacional de Investigaciones Oncológicas, Madrid, Spain and ${ }^{5}$ Department of Paediatric Oncology, Institute of Cancer Research, Sutton, UK

Correspondence: Dr JS Reis-Filho, MD, PhD, FRCPath, The Breakthrough Breast Cancer Research Centre, Institute of Cancer Research, 237 Fulham Road, London SW3 6JB, UK. E-mail: Jorge.Reis-Filho@icr.ac.uk

${ }^{*}$ Current address: Department of Medical Oncology, Hospital del Mar, Passeig Maritim 25, Barcelona 08003, Spain.

Received 18 July 2007; revised 04 February 2008; accepted 10 February 2008
} 
transcription and replication. This enzyme is a known direct molecular target of anthracyclines. We and others demonstrated that TOP2A amplification may predict sensitivity to anthracyclines in the adjuvant setting, ${ }^{8-10,13}$ suggesting that, at least in HER2 + breast cancer, more than one amplified gene may be predictive of response to therapy.

Previous studies of HER2-amplified tumours have demonstrated that the smallest region of amplification (SRA) involving HER2 spans $280 \mathrm{~kb}$ and contains a number of genes in addition to HER2 that have elevated levels of expression, including GRB7, MLN64 (STARD3) and PNMT. ${ }^{14,15}$ Despite the genomic proximity of HER2 and TOP2A, and the fact that TOP2A amplification seems to be restricted to tumours harbouring HER2 amplification, this SRA does not include TOP2A, and there is evidence to suggest that these two genes pertain to separate amplicons. ${ }^{16}$ In fact, tumours harbouring HER2 gene amplification have been shown to display remarkably complex aberrations on the long arm of chromosome $17 .{ }^{17}$ Clearly, while HER2 has been established as the key amplicon driver on chromosome 17q12 in HER2amplified breast cancers, and both HER2 and TOP2A are consistently overexpressed in HER2/TOP2A-co-amplified breast cancers, it is yet to be determined if other genes may also have a role as amplicon drivers in this region. More intriguingly, the specific patterns of gene co-amplification and overexpression, and thus the presence of other putative therapeutic targets, in both HER2-amplified and HER2/ TOP2A-co-amplified tumours remain unknown.

In a recent study by Neve $e t a l^{18}$ the recurrent genomic and gene expression changes of 51 breast cancer cell lines were characterised using a $1-\mathrm{Mb}$ resolution $\mathrm{BAC}$ microarray-based comparative genomic hybridisation platform and Affymetrix high-density oligonucleotide array human HG-U133A chips, respectively, and were found to mirror those of 145 primary breast tumours. Here, we characterise the molecular genetic profile of HER2/TOP2A-co-amplified breast cancers and define the SRA and the boundaries of the $17 \mathrm{q} 12$ amplicon harbouring HER2 and HER2/TOP2A co-amplification (as identified by chromogenic in situ hybridisation (CISH)). In addition, we provide a detailed characterisation of the molecular genetic profiles of tumours in both groups, including other regions of co-amplification in these tumours. The genes within the SRAs on the amplicon 17q12 were correlated with gene expression data to identify additional putative oncogene candidates. Furthermore, given that the accuracy of CISH in defining HER2 and TOP2A amplifications remains contentious, ${ }^{8,11}$ we tested whether CISH can reliably identify cases with TOP2A and HER2 co-amplification.

\section{MATERIALS AND METHODS Breast Cancer Samples}

A series of 295 primary breast cancer cases were assessed for HER2 and TOP2A copy numbers by means of CISH on two tissue microarrays (TMAs). The clinicopathological details of the TMA containing 245 cases have been reported elsewhere. ${ }^{8}$
In brief, this TMA comprises replicate $0.6 \mathrm{~mm}$ cores of 245 invasive breast carcinomas (186 invasive ductal carcinomas, 27 invasive lobular carcinomas, 24 invasive mixed carcinomas and 8 invasive breast carcinomas of other special types) obtained from patients primarily treated with curative surgery (69 mastectomies and 155 wide local excisions) at the Royal Marsden Hospital, London, UK. Patients in this series had been treated with standard anthracycline-based adjuvant chemotherapy. The clinicopathological and immunohistochemical findings of the second TMA containing 50 cases will be the focus of a separate publication. Briefly, this series comprises 50 invasive micropapillary breast carcinomas retrieved from the archives of The Royal Marsden Hospital, London, UK and Department of Biomedical Sciences and Human Oncology, University of Turin, Torino, Italy. All cases were reviewed by CM and JSR-F. Paraffin-embedded blocks of the cases with either HER2 amplification or HER2/TOP2A co-amplification were retrieved from the archive. This study has been approved by the Research Ethics Committees of The Royal Marsden Hospital and University of Turin, Italy.

\section{Breast Cancer Cell Lines}

The cell lines BT474, MDA-MB-361, MDA-MB-453, SKBR3, UACC812 and ZR-75.30, known to harbour HER2 amplification, were grown as previously described. ${ }^{18}$

\section{CISH}

CISH for HER2 and TOP2A was performed as previously described, ${ }^{8}$ using the ready-to-use digoxigenin-labelled SpotLight HER2 and TOP2A amplification probe $\left(\right.$ Zymed $^{\mathbb{R}}$ ) and the biotin-labelled chromosome 17 centromeric probe (CEP17) $\left(\right.$ Zymed $\left.^{\circledR}\right)$. Heat pretreatment of deparaffinised sections consisted of incubation for $15 \mathrm{~min}$ at $98^{\circ} \mathrm{C}$ in $\mathrm{CISH}$ pretreatment buffer (SpotLight tissue pretreatment kit; Zymed $^{\mathbb{R}}$ ) and digested with pepsin for $5 \mathrm{~min}$ at room temperature according to the manufacturer's instructions. In each case, at least 60 non-overlapping nuclei were analysed by two of the authors on a multi-headed microscope. Amplification was defined as the presence of large gene clusters and/or $>5$ gene signals in the nuclei of at least $50 \%$ of neoplastic cells. ${ }^{8}$

\section{DNA Extraction}

Paraffin sections of HER2- and HER2/TOP2A-amplified tumours were stained with nuclear fast red and microdissected with a sterile needle (Terumo Corporation ${ }^{\circledR}$, Japan) under a stereomicroscope (Olympus SZ61 ${ }^{\mathbb{R}}$, Japan) to obtain a percentage of tumour cells in the remaining tissue greater than $75 \%$, as previously described. ${ }^{19}$

Genomic DNA was extracted using a standard proteinase K digestion followed by phenol-chloroform extraction and resuspended in TE buffer $\mathrm{pH} 7.5$, as previously described. ${ }^{19}$ The concentration of the DNA was measured with Picogreen ${ }^{\circledR}$ according to the manufacturer's instructions (Invitrogen, Paisley, UK). Multiplex PCR was performed to 
assess the quality of the DNA. ${ }^{20}$ DNA was extracted from cell lines following standard protocols. ${ }^{21}$

\section{Microarray CGH}

The aCGH platform used for this study was constructed in the Breakthrough Breast Cancer Research Centre and comprises $\sim 16000$ clones, spaced at approximately $100 \mathrm{~kb}$ throughout the genome and spotted onto Corning GAPSIIcoated glass slides (Corning, NY, USA). ${ }^{22}$ This platform contains 418 BACs mapping to chromosome 17, with tiling path coverage of $61.15 \%$ (ie, overlapping BACs). For the remaining $38.85 \%$, the median interval between BACs was $106.90 \mathrm{~kb}$ (range $=0.216-897.82 \mathrm{~kb}$ ). Labelling, hybridisation and washes were carried out as previously described. ${ }^{22}$ Briefly, $400 \mathrm{ng}$ of test and reference genomic DNA was labelled with Cy3-dCTP or Cy5-dCTP (Amersham BioScience, Amersham, UK) using a Bioprime ${ }^{\circledR}$ labelling kit (Invitrogen), according to the manufacturer's protocol modified to incorporate $0.6 \mathrm{mM} \mathrm{dCTP}$, and $1.2 \mathrm{mM}$ dATP, dGTP and dTTP. The unincorporated nucleotides were removed with MinElute ${ }^{\circledR}$ purification columns (Qiagen Ltd, UK). All experiments were performed in duplicate ('dye swaps') to minimise dye biases.

\section{Image Acquisition and Data Analysis}

The aCGH slides were scanned using an Axon 4000B scanner (Axon Instruments, Burlingame, CA, USA) and images were processed using Genepix Pro 4.0 image analysis software (Axon Instruments). The $\log _{2}$ ratios were normalised for spatial- and intensity-dependent biases using a two-dimensional loess regression and then averaged across the 'dye swaps'. This left a final data set of 14277 clones with unambiguous mapping information according to the March 2006 build (hg18) of the human genome (http://www.ensembl.org). Data were smoothed using a local polynomial adaptive weights smoothing (aws) procedure for regression problems with additive errors. Thresholds for defining genomic gains and losses were obtained using data from unamplified female $v s$ female and female $v s$ male genomic DNA, as previously described. ${ }^{22}$ A categorical analysis was applied to each clone on the array after classification as gain, loss or no change according to their smoothed $\log _{2}$ ratio values. Smoothed $\log _{2}$ ratio values $<-0.12$ were categorised as losses, those $>0.12$ as gains, and those in between as unchanged. Amplifications were defined as smoothed $\log _{2}$ ratio values $>0.4$. Data processing and analysis were carried out in R 2.0.1 (http://www.r-project.org/) and BioConductor 1.5 (http://www.bioconductor.org/), making extensive use of modified versions of the packages aCGH, marray and aws in particular.

\section{Statistical Analysis for Differential Gene Expression}

Statistical analysis was carried out using SPSS statistical package. Affymetrix mRNA gene expression data from 54 breast cancer cell lines were retrieved from the
Supplementary Material of Neve et al. ${ }^{18}$ All cell lines that were not classified as luminal or basal like, that have proven not to be breast cancer cell lines (ie MDA-MB-435, which is a melanoma cell line) and that were reported to be positive for HER2 and could not be profiled in this study (ie HCC1954, HCC202, SUM190PT and SUM225CWN) were excluded. Expression of genes pertaining to the SRA of HER2-amplified cases and HER2/TOP2A-co-amplified samples were collated in a SPSS spreadsheet. Analysis of the correlation between HER2 amplification and expression of genes pertaining to the SRA of HER2 amplicon was performed with Mann-Whitney $U$-test. Analysis of the correlation between HER2/TOP2A co-amplification and expression of genes pertaining to the SRA defined in cases harbouring HER2/TOP2A amplification was performed with Mann-Whitney $U$-test. We also compared the expression of genes pertaining to the SRA of HER2/TOP2A-co-amplified cases in cell lines with HER2 amplification $v$ s those with HER2/TOP2A co-amplification; owing to the limited number of cell lines $(n=2$ for HER2/TOP2A co-amplified and $n=4$ for HER2 amplified), the two-tailed Student's $t$-test was employed.

\section{Quantitative Real-Time (qRT)-PCR}

We then investigated the expression of genes shown to be significantly overexpressed in cell lines with HER2/TOP2A co-amplification when compared to those with only HER2 amplification in a series of HER2-amplified and HER2/ TOP2A-co-amplified breast cancers by means of quantitative real-time (qRT)-PCR.

The 5 HER2- and the 10 HER2/TOP2A-co-amplified cancers analysed in this study and additional 10 HER2amplified and 10 HER2/TOP2A-co-amplified breast cancers were subjected to RNA extraction. RNA was extracted from FFPE tissue using the RNeasy FFPE RNA Isolation Kit (Qiagen Ltd) as per manufacturer's instructions, with the modification of one $30 \mathrm{~min}$ xylene treatment at $37^{\circ} \mathrm{C}$. An additional DNase treatment step was performed; following RNA extraction, $6 \mathrm{U}$ of DNase (Ambion) was incubated with RNA at $37^{\circ} \mathrm{C}$ for $1 \mathrm{~h}$, to enable efficient DNA digest. All RNA quantification and qualification were performed using the Agilent 2100 Bioanalyzer with RNA Nano LabChip Kits (Agilent Biosystems). Criterion for use in reverse transcription was a concentration of $>75 \mathrm{ng} / \mu \mathrm{l}$. Twelve HER2amplified cancers (5 subjected to array CGH analysis +7 additional cases) and 15 HER2/TOP2A-co-amplified cases (10 subjected to array CGH analysis +5 additional cases) rendered optimal results. Reverse transcription was performed with Superscript III (Invitrogen) using $400 \mathrm{ng}$ of RNA per reaction. Triplicate reactions were performed for each sample $(\mathrm{RT}+)$, in addition to an RT-reaction to check for the absence of detectable DNA contamination.

qRT-PCR was performed using TaqMan ${ }^{\circledR}$ chemistry on the ABI Prism 7900HT (Applied Biosystems), using the standard curve method. ${ }^{23}$ Assays were purchased from Applied Biosystems, with the exception of TBP where primers 
and probes (Operon; forward: GCCCGAAACGCCGAATAT, reverse: CGTGGCTCTCTTATCCTCATGA) were designed using Primer Express software (Applied Biosystems) and sequences were checked for specificity using BLAST. All selected amplicons were less than $85 \mathrm{bp}$ to accommodate the degraded nature of the RNA. In addition, three reference genes (TBP, TFRC and MRPL19) were used, having been previously selected as effectively normalising for degradation of RNA. Each gene of interest was normalised to the geometric mean of the three references. The Mann-Whitney $U$-test was applied to determine significance.

\section{RESULTS}

\section{Molecular Genetic Profiles of HER2 and HER2/TOP2A- Amplified Cases}

Genome-wide aCGH profiling of HER2-amplified and HER2/TOP2A-co-amplified breast cancers revealed several genomic regions that were consistently gained or lost in association with the HER2 or HER2/TOP2A amplification. These regions are illustrated in Figure 1. Although some of these changes were common to several tumours, the profiles of the tumours were heterogeneous as shown in Figure 1. In fact, 12 out of $15(80 \%)$ cases showed a 'firestorm' pattern as described by Hicks et al, ${ }^{24}$ presenting clustering of multiple amplicons on single chromosome arms; ${ }^{24}$ three cases showed a 'sawtooth' pattern (many narrow segments of duplication and deletion affecting all chromosomes) and none of the cases demonstrated a 'simplex' pattern (broad segments of duplication and deletion comprising entire chromosomes or chromosome arms). If classified according to the patterns identified by Chin et al, ${ }^{25} 12,3$ and 0 would be categorised as 'amplifiers' (low-level gains and losses and recurrent amplifications), 'complex' (many low level copy number alterations) or '1q/16q/simple' (very few copy number changes), respectively. The three cases with a 'sawtooth'/complex pattern belonged to the HER2/TOP2A-co-amplified group (Figure 1). Interestingly, only 2 out of the $15(13.3 \%)$ cases analysed displayed losses of the whole long arm of chromosome 16 (Figure 1).

\section{The 17q12-q21 Amplicon in HER2 and HER2/TOP2A Breast Cancers}

Following DNA extraction and quality evaluation, 15 cases with HER2 gene amplification as defined by CISH were subjected to aCGH, of which 10 also harboured TOP2A amplification (Table 1). The minimal region of amplification in the 15 HER2-amplified cases on 17q12-q21 comprised four BACs with a total length of $746.48 \mathrm{~kb}$, from 34730.32 to $35476.80 \mathrm{~kb}$ (Figure 2a). This region encompasses $>20$ genes, including HER2, PERLD1, PNMT, PPP1R1B, GSDML, PSMD3, STARD3, THRAP4, TCAP, GRB7, THRA and PPARBP, reported to be overexpressed when amplified. ${ }^{12,15-18,21}$

In the 10 cases with HER2/TOP2A co-amplification, the smallest region of overlap extended from 34730.32 to $36547.20 \mathrm{~kb}$, comprising a region of $1816.88 \mathrm{~kb}$ and encompassing $>50$ genes (Figure 2b). Apart from the genes pertaining to the HER2 amplicon and TOP2A, this region included additional genes that are reported to be overexpressed when amplified: cancer susceptibility candidate 3 (CASC3), retinoic acid receptor alpha (RARA), cell division cycle homologue 6 (CDC6), SWI/SNF-related, matrix-associated, actin-dependent regulator of chromatin, subfamily e, member 1 (SMARCE1) and keratin 10 (KRT10). ${ }^{12,16-18,22,25}$

Owing to the selection of criteria of samples harbouring HER2/TOP2A co-amplifications, the prevalence of TOP2A gene deletions could not be analysed.

\section{The 17q12-q21 Amplicon in Breast Cancer Cell Lines with HER2 Amplification}

The cell lines BT474, MDA-MB-361, MDA-MB-453, SKBR3, UACC812 and ZR-75.30 have been shown to harbour HER2 gene amplification. ${ }^{18}$ In our study, the HER2 amplicon in these cell lines is remarkably similar to that seen in the 15 breast cancers encompassing the region between 34730.32 and $35476.80 \mathrm{~kb}$ and the BACs RP11-62N23, RP11-94L15, RP11-610O22 and RP11-32H6 (Supplementary Table 1). TOP2A amplification was only observed in the cell lines SKBR3 and UACC812; MDA-MB-361, MDA-MB-453 and ZR-75.30 harboured TOP2A gene deletions and BT474 showed normal TOP2A copy number (Figure 2c). Complex rearrangements on $17 \mathrm{q}$, similar to those observed in our series of HER2 and HER2/TOP2A-co-amplified cases, were also found in the cell lines: all cell lines showed rearrangements distal to HER2 amplicon, whereas rearrangements proximal to HER2 amplicon were only seen in MDA-MB-361 and ZR-75.30. Genome-wide analysis of the cell lines revealed complex 'firestorm' patterns in all but MDA-MB-453 cells, which displayed a complex 'sawtooth' pattern (Supplementary Figure 1).

\section{Differential Expression of Genes Mapping to the SRA of the HER2 and TOP2A Amplicons in Breast Cancer Cell Lines and Human Tumours}

Our analysis, including 46 breast cancer cell lines, ${ }^{18}$ demonstrated that the expression of 9 genes pertaining to the SRA of HER2 amplicon was strongly correlated with amplification of this genomic region in breast cancer cell lines: PPARB, IKZF3, GRB7, PERLD1, STARD3, PNMT, ZNFN1A3 and ERBB2 (all $P<0.05$, Mann-Whitney $U$-test) (Supplementary Table 2). When we compared the expression of each gene within the HER2 SRA in each cell line with its median expression in all cell lines, we observed that only GRB7, PERLD1, STARD3, PNMT and ERBB2 were consistently overexpressed in all HER2-amplified cell lines.

When we compared the expression of each gene within the HER2/TOP2A SRA in each cell line with its median expression in all cell lines, we observed that CCR7, CDC6, CRKRS, CSF3, TNS4, GRB7, PERLD1, CASC3, STARD3, NEUROD2, NR1D1, PNMT, PPARBP, GSDML, PSMD3, RARA, SMARCE1, TCAP, THRA, TOP2A, THRAP4 and HER2 were 

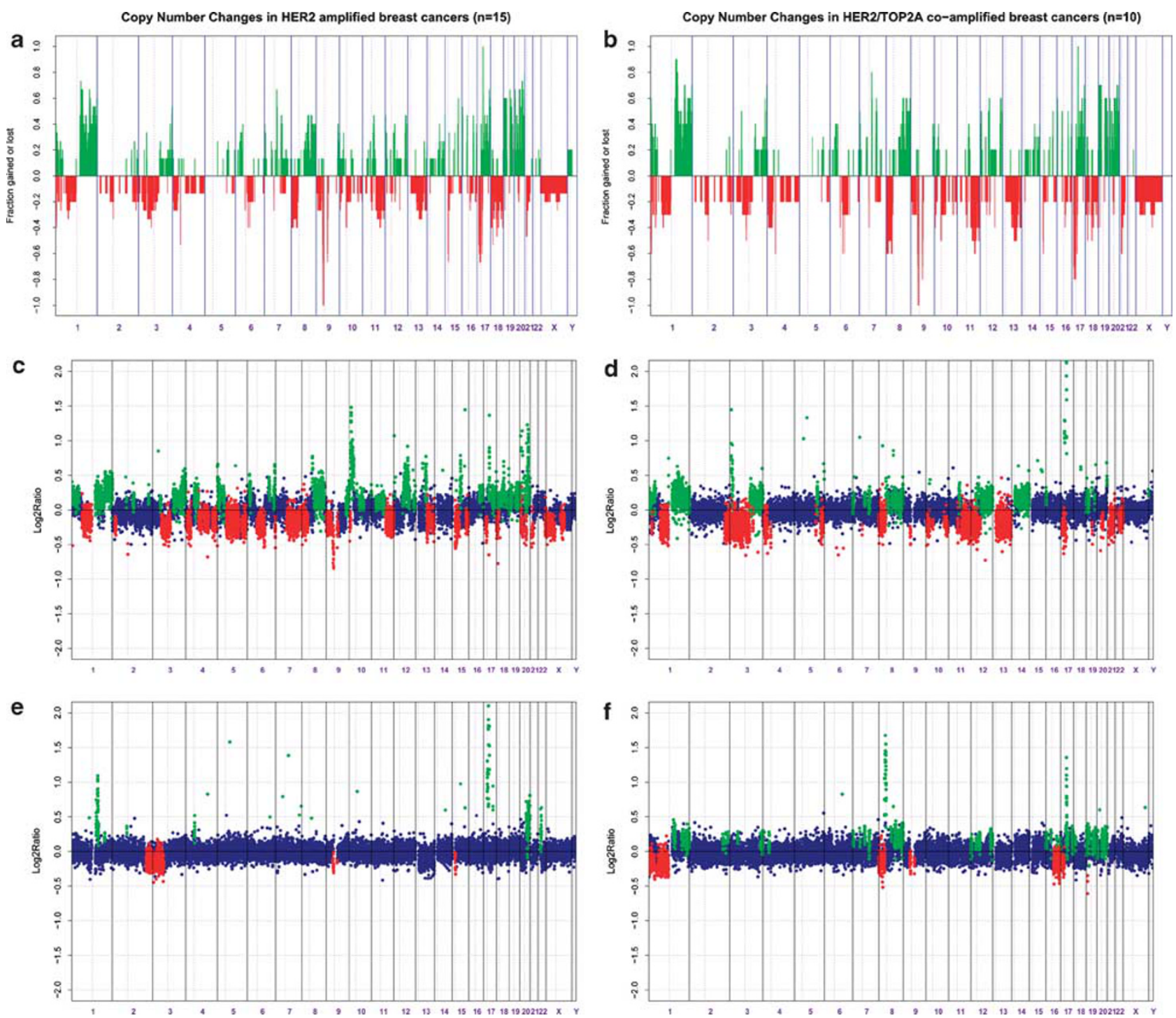

Figure 1 Array CGH analysis of HER2- and HER2/TOP2A-amplified breast cancers. (a) Frequency plot of chromosomal gains and losses in 15 HER2-amplified breast cancers. (b) Frequency plot of chromosomal gains and losses in the subset of HER2/TOP2A-co-amplified breast cancers. The proportion of tumours in which each clone is gained (green bars) or lost (red bars) is plotted ( $Y$ axis) for each BAC clone according to genomic location ( $X$ axis). Vertical dotted lines represent chromosome centromeres. (c-f) Representative genome plots of HER2/TOP2A-co-amplified breast carcinomas showing either a complex amplifier/ firestorm pattern $(\mathbf{c}, \mathbf{d})$ or a complex/sawtooth pattern $(\mathbf{e}, \mathbf{f})$. $\log _{2}$ ratios are plotted on the $Y$ axis against each clone according to genomic location on the $X$ axis. The centromere is represented by a vertical dotted line. BACs categorised as displaying genomic gains as defined by aws ratios $>0.12$ are highlighted in green and those categorised as genomic losses as defined by aws ratios $<-0.12$ are highlighted in red. BACs with aws ratios between -0.12 and 0.12 were considered unchanged and highlighted in blue.

consistently overexpressed in the two HER2/TOP2A-coamplified cell lines (ie SKBR3 and UACC812). Of these genes, the following showed a statistically significant correlation with HER2/TOP2A co-amplification: CCR7, CDC6, CRKRS, CSF3, GRB7, CASC3, STARD3, PNMT, PPARB, GSDML, RARA, SMARCE1, TOP2A, THRAP4 and HER2 (all $P<0.05$, Mann-Whitney $U$-test) (Supplementary Table 2).

When we compared the expression of each gene pertaining to the HER2/TOP2A SRA in each cell line with its median expression in the six HER2-amplified cell lines, we observed that CCR7, CDC6, CRKRS, CSF3, TNS4, KRT10, CASC3,
PNMT, PPARBP, PRO2521, PSMD3, RARA, SMARCE1, TCAP, THRA, TOP2A and THRAP4 were consistently overexpressed in the two HER2/TOP2A-co-amplified cell lines. Out of these genes, only CDC6, CASC3, SMARCE1, RARA and TOP2A were statistically significantly expressed at high levels in HER2/TOP2A-co-amplified cases $(P<0.05$, Student's $t$-test). We next compared the expression of these genes and HER2 and KRT10 (two genes not differentially expressed in the two groups) in a series of 12 HER2-amplified and 15 HER2/TOP2A-co-amplified invasive breast cancers by means of qRT-PCR (Table 2). No significant differences between the 
Table 1 Summary of cases subjected to chromogenic in situ hybridisation and microarray-based comparative genomic hybridisation

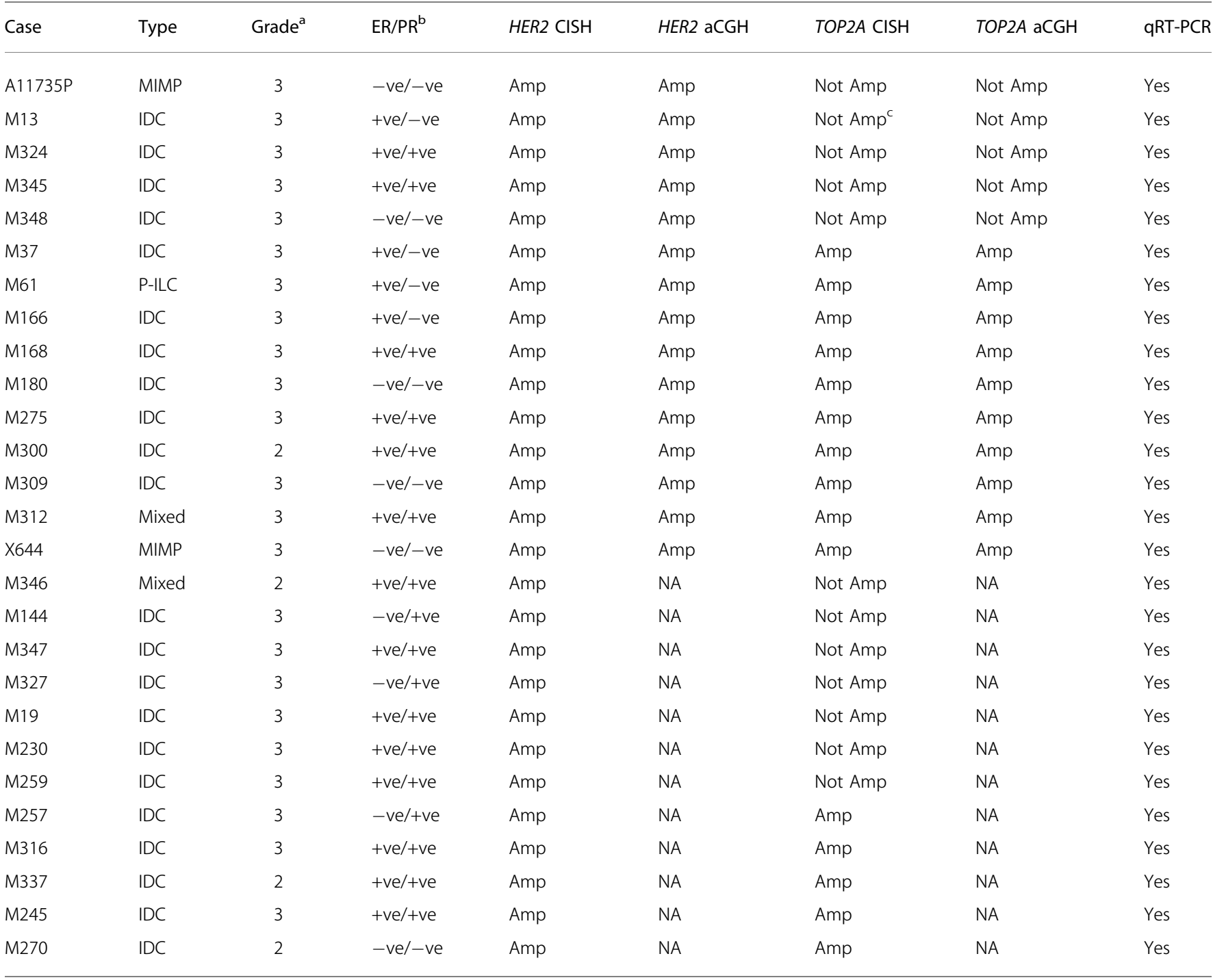

a Bloom-Richardson-Scarff histological grade.

${ }^{b}$ As defined by an Allred score $\geq 3$.

'This case showed low-level copy 'amplification' using only the TOP2A probe. When ratios TOP2A:CEP17 were devised, the case lacked TOP2A gene amplification. -ve, negative; +ve, positive.

aCGH, microarray-based comparative genomic hybridisation; Amp, amplified; CISH, chromogenic in situ hybridisation; IDC, invasive ductal carcinoma of no special type; MIMP, mixed invasive micropapillary carcinoma; mixed, mixed invasive ductal and lobular carcinoma; not Amp, not amplified; NA, not assessable due to failed quality control PCR; P-ILC, pleomorphic lobular carcinoma.

mitotic counts of these HER2 and HER2/TOP2A-amplified cancers were observed. Our results demonstrate that CASC3 $(P<0.0001), \quad C D C 6 \quad(P<0.0001), \quad R A R A \quad(P<0.001)$, SMARCE1 $(P<0.005)$ and TOP2A $(P<0.01)$ were differentially expressed in both subgroups.

CISH and aCGH Analysis of HER2 and TOP2A Gene Status From a total of 295 samples analysed by CISH on two TMAs, 276 cases yielded optimal results for both HER2 and TOP2A probes. Applying the guidelines ${ }^{26}$ for HER2 and TOP $2 A$
CISH amplification testing, $43(15.6 \%)$ displayed HER2 amplification of which $24(8.7 \%)$ also displayed TOP $2 A$ amplification (Figure 3). There were no cases with TOP2A amplification in the absence of HER2 amplification. In one case of HER2/TOP2A co-amplification, while HER2 was amplified throughout the tumour, TOP $2 A$ amplification was heterogenous, with areas containing $>10$ copies of TOP $2 \mathrm{~A}$ signals per nucleus (70\% tumour) and others with cells harbouring $<5$ gene copies per nucleus ( $30 \%$ tumour). One case harboured high-level HER2 amplification (ie $>10$ gene 
a

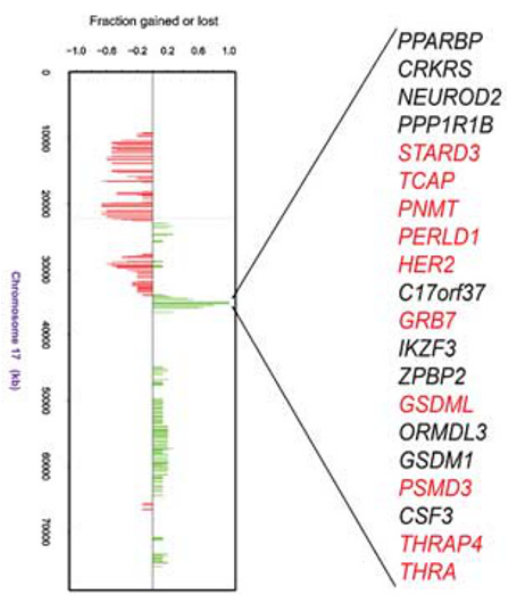

b $\quad H E R 2 / T O P 2 A$ amplified breast cancers $(n=10)$

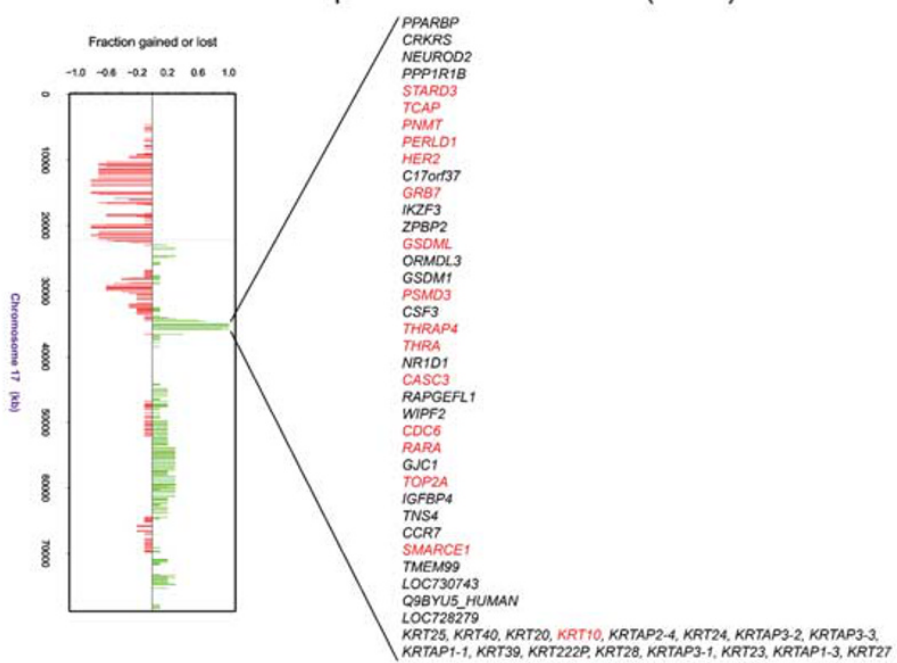

C $\quad$ BT474

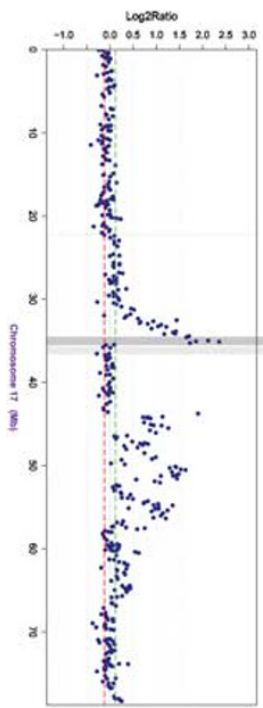

MDA-MB-361

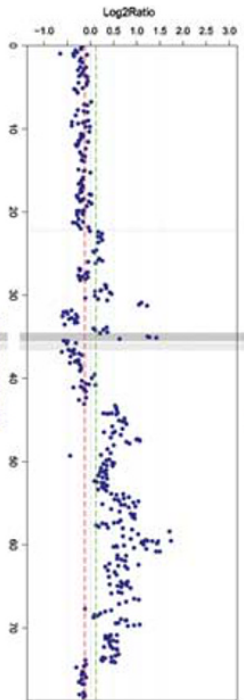

$(n=15)$

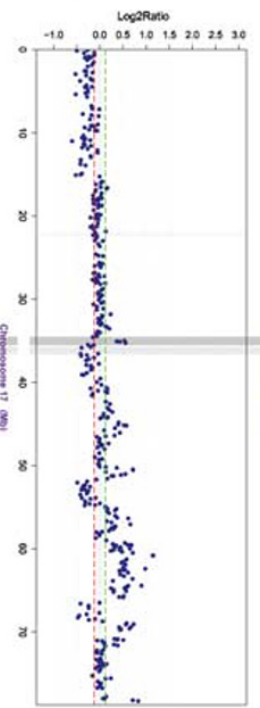

SKBR3

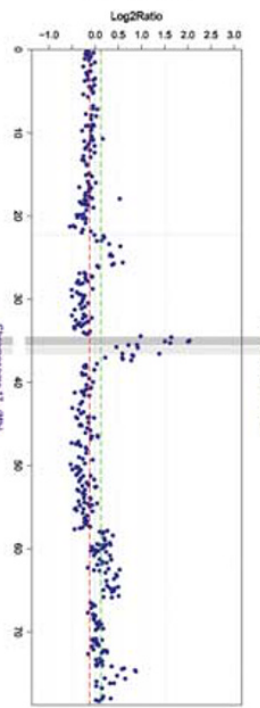

ZR-75.30

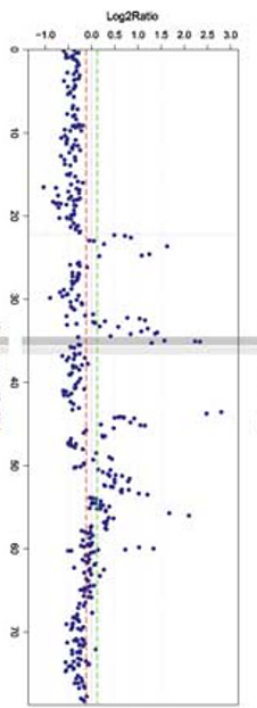

UACC812

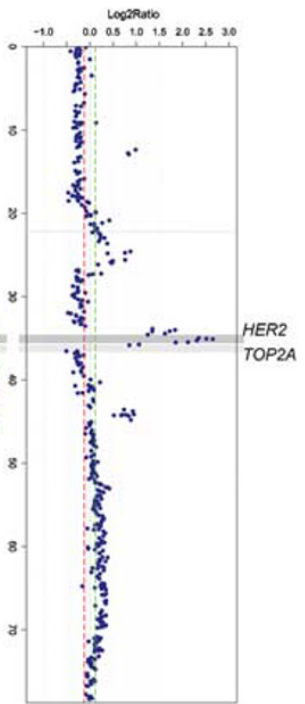

Figure 2 Frequency of amplifications and deletions on chromosome 17 in 15 HER2-amplified breast cancers (a) and in the subset ( $n=10)$ of HER2/TOP2Aco-amplified breast cancers (b). The proportion of tumours in which each clone is amplified (green bars) or lost (red bars) is plotted ( $X$ axis) for each BAC clone according to genomic location ( $Y$ axis). Horizontal dotted lines represent chromosome centromeres. The smallest regions of overlap and the genes mapping to these regions in HER2-amplified cancers and HER2/TOP2A-co-amplified breast cancers are highlighted on the right. In red, genes whose expression is reported to correlate with gene amplification. ${ }^{14-18,21}$ (c) Representative chromosome 17 plots of five HER2-amplified breast cancer cell lines. Note that out of these cell lines, only SKBR3 and UACC812 harboured HER2/TOP2A co-amplification. MDA-MB-361, MDA-MB-453 and ZR-75.30 displayed deletions of the TOP2A gene. $\log _{2}$ ratios are plotted on the $X$ axis against each clone according to genomic location on the $Y$ axis. The centromere is represented by a horizontal dotted line. HER2 and TOP $2 A$ amplicons are highlighted by dark and light grey boxes, respectively.

copies per nucleus), but low-level TOP2A amplification (average of 5.2 TOP2A copies per nucleus). As recommended by the current guidelines for CISH assessment, we derived the TOP2A/CEP17 ratios for the case with TOP2A low-level amplification, which revealed no TOP2A amplification.

In four cases, BACs mapping to the pericentromeric region of $17 \mathrm{q}$ also showed high-level copy number gains. However, no difference in CEP17 copy numbers by CISH was seen when cases with and without pericentromeric $17 \mathrm{q}$ gains were analysed with chromosome centromere 17 CISH probes:
CEP17 copy numbers ranged from 1.3 to 2.6 in cases with these pericentromeric gains, whereas in the remaining cases the number of CEP17 signals ranged from 1.4 to 2.3 ( $t$-test, not significant).

\section{Other Genomic Aberrations on Chromosome 17}

Given the reported complexity of genomic rearrangements on chromosome 17 in cases with HER2 amplification, ${ }^{17}$ we performed a detailed analysis of the molecular genetic aberrations affecting this chromosome. Two discrete regions of 
Table 2 Quantitative real-time PCR analysis of genes mapping to HER2/TOP2A amplicon in invasive breast cancers

\begin{tabular}{|c|c|c|c|c|}
\hline Gene & TOP2A not amplified $(n=12)$ & TOP2A amplified $(n=15)$ & Fold change & $P$-value ${ }^{a}$ \\
\hline CASC3 & $0.38 \pm 0.07$ & $1.50 \pm 0.12$ & 3.93 & $<0.0001$ \\
\hline RARA & $5.85 \pm 1.2$ & $6.55 \pm 0.96$ & 4.74 & $<0.001$ \\
\hline SMARCE1 & $1.26 \pm 0.41$ & $5.99 \pm 1.33$ & 2.82 & $<0.005$ \\
\hline ERBB2 & $0.05 \pm 0.02$ & $0.26 \pm 0.05$ & 1.12 & NS \\
\hline$K R T 10^{\mathrm{b}}$ & NA & $0.25 \pm 0.21$ & NA & NS \\
\hline
\end{tabular}

a Mann-Whitney U-test.

${ }^{b}$ Detectable levels of KRT10 were seen in only one HER2-amplified cancer and in three HER2/TOP2A-co-amplified cancers.

NA, not assessable; NS, not significant.
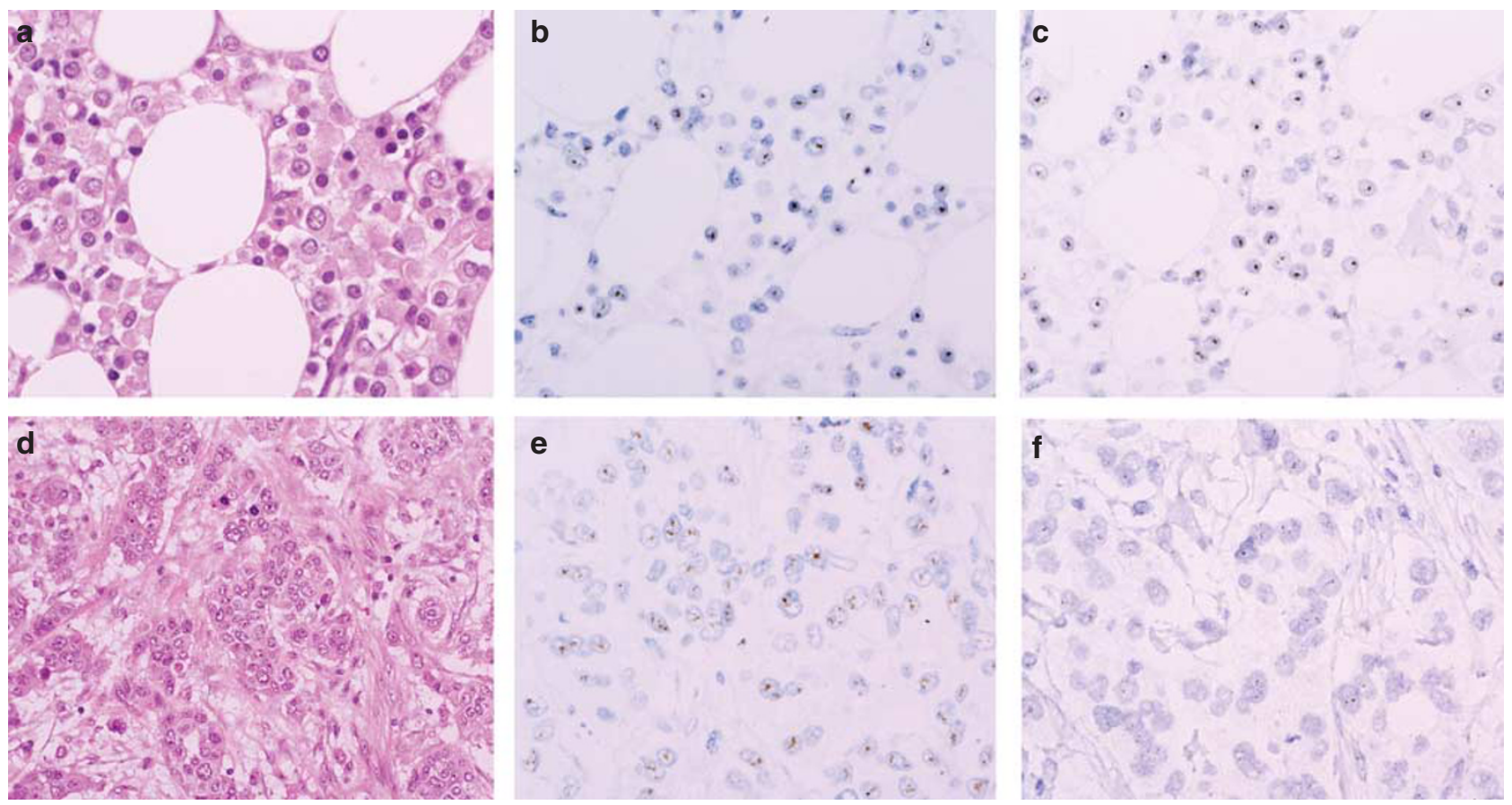

Figure 3 HER2-amplified invasive breast carcinomas. Grade III pleomorphic lobular carcinoma (a) with HER2 (b) and TOP2A (c) co-amplification. Grade III invasive ductal carcinoma (d) harbouring HER2 gene amplification (e) and lacking TOP2A gene amplification (f). (a, d) H\&E; (b, e) chromogenic in situ hybridisation with probes for the HER2 gene; (c, f) chromogenic in situ hybridisation with probes for the TOP2A gene; original magnification $\times 200$ (d); $\times 400(\mathbf{a}-\mathbf{c}, \mathbf{e}, \mathbf{f})$.

deletion but no amplifications were observed on $17 \mathrm{p}$ (Supplementary Table 3). Only one case harboured a genomic deletion mapping to TP53 locus (case X644). Recurrent losses on $17 \mathrm{p} 13.1-\mathrm{p} 11.2$ were seen in nine cases, with two smallest regions of overlap being identified: $17 \mathrm{p} 12(12930-13775 \mathrm{~kb})$ and 17p11.2 (16396-16 800 kb), both of which are known copy number polymorphisms (http://projects.tcag.ca/variation/) and frequently deleted in normal genomic DNA. ${ }^{27,28}$ The second region of deletion affected 10 cases and mapped to 17p11.2-pcen (18287-22 $767 \mathrm{~kb})$, with two smallest regions of overlap, one mapping to $18287-18697 \mathrm{~kb}$ and the other to $19859-21843 \mathrm{~kb}$. The latter has not been reported to map to a copy number polymorphism and encompasses the following genes: mitogen-activated protein kinase kinase 3 (MAP2K3), potassium channel inwardly rectifying subfamily j member 12 (KCNJ12), spectrin and coiled-coil domains protein 1 (SPECC1), dehydrogenase/reductase (SDR family) member 7B (DHRS7B), transmembrane protein 11 (TMEM11), C17orf51 and family with sequence similarity 27-like (FAM27L). 
Unlike 17p, 17q frequently displayed gains rather than losses of genomic material (Supplementary Table 3). The only recurrent region of deletion found on $17 \mathrm{q}$ mapped to 17q11.2-q12 (27 614-34 174 Mb); its smallest region of overlap mapped to $17 \mathrm{q} 12$ (29014-29555 Mb), which was seen in eight cases. This region encodes the neuronal amiloride-sensitive cation channel 1 (ACCN1), whose expression does not seem to be regulated by deletions or gains of genomic material. ${ }^{18,21}$ In addition to the HER2 and TOP2A amplicons, six other regions of recurrent amplification were observed on the long arm of chromosome 17 (Table 3).

\section{Recurrent Co-Amplifications in HER2-Amplified Cases}

We studied regions of amplification associated with amplification of HER2 and/or TOP2A. We found 21 additional regions of recurrent amplification throughout the genome. We next analysed the SRA within each amplicon (Table 3). After excluding all regions included in the SRAs with reported copy number polymorphisms (http://projects.tcag.ca/ variation/), 10 regions of recurrent amplifications in HER2amplified cases were identified, three of which mapped to chromosome 20q (Table 3).

\section{DISCUSSION}

Genome-wide analysis of HER2- and HER2/TOP2A-amplified cases revealed that the large majority of these breast cancers and breast cancer cell lines display a 'firestorm'/ 'amplifier' genomic pattern, which is often seen in a subgroup of luminal and HER2 cancers, ${ }^{25}$ and less commonly seen in grade I and basal-like breast cancers. ${ }^{18,21,24,25}$ These findings suggest that different molecular subgroups of breast cancers are associated with distinct types of genetic instability and/or evolve through distinct genetic pathways. Unlike grade I breast cancers that harbour deletions of the whole of $16 \mathrm{q}$ in $65-85 \%$ of cases, ${ }^{29,30}$ only $15 \%$ of HER2-amplified breast cancers display this genetic aberration. These findings suggest that progression from grade I to grade III breast cancer is an uncommon biological phenomenon and that HER2-amplified breast cancers are unlikely to originate from luminal A cancers, which are characterised by concurrent gains of $1 \mathrm{q}$ and deletions of $16 \mathrm{q} .{ }^{21}$

The HER2 SRA identified in this study encompasses that described by Kauraniemi et al ${ }^{14,15}$ and Orsetti et al. ${ }^{17}$ Interestingly, in all breast cancers and cell lines analysed here, four BACs (RP11-62N23, RP11-94L15, RP11-610O22 and RP11$32 \mathrm{H} 6)$ were consistently amplified. The reason why the HER2 SRA defined in this study is apparently larger than that reported by Kauraniemi et al ${ }^{15}(\sim 280 \mathrm{~kb})$ stems from the updated mapping positions of BAC clones in more recent genome builds. In that study, ${ }^{15}$ the boundaries of the 'core region' of HER2 amplicon were defined by BAC clones RP11390P24 and RP11-387H17, which according to the current genome build (hg18, http://www.ensembl.org), map to $34.80-34.98 \mathrm{Mb}$ and $35.23-35.44 \mathrm{Mb}$, respectively. Hence, the actual 'core region' of HER2 amplicon defined by Kauraniemi et $a l^{15}$ spans approximately $633 \mathrm{~kb}$.

In HER2-amplified tumours, the SRA encompassed HER2 and PPARBP, PPP1R1B, STARD3, TCAP, PNMT, PERLD1, GRB7, GSDML, PSMD3 and THRAP4, of which all but $P P A R B P$ and PPP1R1B have been reported to correlate with gene expression. ${ }^{14,15,17,18,21}$ Our analysis of publicly available data on HER2-amplified and non-amplified breast cancer cell lines $^{18}$ revealed that PPARB, GRB7, PERLD1, STARD3 and $P N M T$ are also overexpressed when co-amplified with HER2. siRNA-mediated downregulation of GRB7 and STARD3 in HER2-amplified breast cancer cell lines is reported to lead to decreased cell proliferation and cell cycle progression, ${ }^{31}$ suggesting that amplification and overexpression of other genes mapping to the SRA may also contribute to tumour growth. This is further corroborated by preclinical models, which have shown that a Grb7 peptide inhibitor in combination with Herceptin treatment enhances the inhibitory effect on the proliferation of SKBR3 cells and inhibit the proliferation of MDA-MB-361 cells. ${ }^{32}$ Taken together, these findings suggest that HER2 may not be the sole oncogene in this amplicon.

This study provides the first fine mapping of the 17q12-q21 amplicon in breast cancers harbouring HER2/ TOP2A co-amplification (SRA: $34730.322-36547.206 \mathrm{~kb}$ ). Apart from the genes known to be amplified and overexpressed in cases harbouring HER2 amplification, TOP2A, CASC3, CDC6, RARA and SMARCE1 are overexpressed in HER2/TOP2A-co-amplified breast cancers and breast cancer cell lines. CASC3 or MLN51 is overexpressed in breast cancers and encodes a core component of the exon junction protein complex, which is deposited on spliced mRNAs at exon-exon junctions and functions in nonsensemediated mRNA decay. ${ }^{33}$ RARA is frequently rearranged in promyelocytic leukaemias and has recently been reported to be a separate amplicon in breast cancers with complex patterns of $17 \mathrm{q}$ rearrangements. ${ }^{34}$ Our findings demonstrate that RARA does not form a separate amplicon and is actually part of TOP2A amplicon. ${ }^{34}$ The SMARCE1 or BAF57, is part of the large ATP-dependent chromatin remodelling complex SWI/SNF, which is required for transcriptional activation of genes normally repressed by chromatin remodelling. This gene is reported to mediate ER $\alpha$ signalling in breast cancer cells. ${ }^{35}$ The CDC6, which is regulated by E2F proteins, encodes a protein essential for the initiation of DNA replication. Amplification and overexpression of CDC6 result in INK4/ARF-dependent transcriptional repression, recruitment of histone deacetylases and heterochromatinisation of the INK4/ARF locus, and a concurrent decrease in p16 expression. ${ }^{36}$ These amplified and overexpressed genes may be additional amplicon drivers with important biological roles in HER2/TOP2A co-amplified breast cancers. Further studies to test whether these genes could also be explored as additional therapeutic targets are warranted. 
Table 3 Summary of smallest regions of recurrent amplification in 15 HER2-amplified invasive breast cancers

\begin{tabular}{|c|c|c|c|c|c|c|}
\hline Cytoband & Start $(\mathrm{kb})$ & End (kb) & CNP & $\begin{array}{l}\text { Amplified } \\
\text { cases (TOP2A } \\
\text { amplified) }\end{array}$ & Genes & MicroRNAs \\
\hline 1q23.2-23.3 & 158012.91 & 158762.75 & No & 2 & $\begin{array}{l}\text { NHLH1, ATP1A2, CR625159, VANGL2, KIAA1355, VSIG8, } \\
\text { SLAMF8, IGSF9, PEA15, TAGLN2, KCNJ10, PIGM, SLAMF9, } \\
\text { SLAMF6, SUMO1, IGSF8, KCNJ9, ATP1A4, CCDC19, CASQ1, } \\
\text { WDR42A, NESG1, PEX19, UNQ1938, DUSP23, COPA, } \\
\text { NCSTN, FCRL6 }\end{array}$ & \\
\hline $1 \mathrm{q} 32.1-32.2$ & 204706.01 & 208215.77 & Yes & $2(1)$ & $\begin{array}{l}\text { DYRK3, G0S2, C1orf74, CD34, C4BPB, ZCYTO10, LGTN, } \\
\text { AK123177, C4BPA, PFKFB2, LAMB3, AY882314, IL10, IL19, } \\
\text { C1orf107, CR1, IL20, IRF6, FCAMR, TRAF3IP3, SYT14, PLXNA2, } \\
\text { IKBKE, C1orf116, CD55, CD46, C1orf147, RED, IL24, CAMK1G, } \\
\text { FAIM3, FKSG87, CR2, BC063704, PIGR, YOD1, RASSF5, CR1L, } \\
\text { MAPKAPK2, DAF, HSD11B1 }\end{array}$ & $\begin{array}{l}\text { hsa-mir-29c, } \\
\text { hsa-mir-29b-2, } \\
\text { hsa-mir-205 }\end{array}$ \\
\hline $1 q 41-q 42.12$ & 219587.07 & 223218.85 & Yes & $2(1)$ & $\begin{array}{l}\text { TP53BP2, CNIH4, C1orf58, DISP1, RP11-367A10.1-001, TAF1A, } \\
\text { TLR5, MIA3, FBXO28, CNIH3, WDR26, KIAA1822L, NVL, C1orf65, } \\
\text { DUSP10, C1orf80, CAPN2, C1orf67, DKFZp6666185, SUSD4, } \\
\text { FLJ43505, CR625980, DKFZP586E1222, DEGS1 }\end{array}$ & \\
\hline $1 \mathrm{q} 43$ & 234816.89 & 236546.39 & Yes & $2(1)$ & HEATR1, MTR, ZP4, RYR2, ACTN2, MT1P2 & \\
\hline $1 q 44$ & 243448.79 & 244960.36 & Yes & $2(1)$ & SCCPDH, KIF26B, TFB2M, C1orf71, DQ593601, SMYD3 & \\
\hline $6 p 21.1$ & 44057.11 & 44543.40 & No & $2(1)$ & $\begin{array}{l}\text { HSP90AB1, ENT1, SPATS1, SLC29A1, SLC35B2, MGC33600, } \\
\text { MRPL14, NFKBIE, CDC5L, TMEM63B, AARS2, MGC45491, CAPN11 }\end{array}$ & \\
\hline $8 q 21.2$ & 86717.11 & 86899.50 & Yes & $2(2)$ & REXO1L1 & \\
\hline $11 q 13.3$ & 68461.88 & 68945.85 & No & $3(2)$ & OCIM, MRGPRD, MYEOV, IGHMBP2, TPCN2, MRGPRF & \\
\hline $17 q 11.2$ & 22766.90 & 25931.27 & Yes & $4(3)$ & $\begin{array}{l}\text { SUPT6H, POLDIP2, FLOT2, PIGS, SARM1, PCFT, TIAF1, ERAL1, } \\
\text { SEZ6, FLJ00234, TMEM97, TP53I13, CRYBA1, DHRS13, LOC201229, } \\
\text { GIT1, NUFIP2, PIPOX, PHF12, ALDOC, RAB34, IFT20, UNC119, TRAF4, } \\
\text { NLK, C17orf63, NEK8, SLC13A2, SDF2, FLJ00295, PROCA1, } \\
\text { DKFZP547N203, FOXN1, TLCD1, VTN, RPL23A, SPAG5, FLJ40504, } \\
\text { LOC116236, MYO18A, UNQ419, BCOX, TNFAIP1, TAOK1, } \\
\text { SEBOX, C17orf32 }\end{array}$ & $\begin{array}{l}\text { hsa-mir-195, } \\
\text { hsa-mir-497, } \\
\text { hsa-mir-451, } \\
\text { hsa-mir-144, } \\
\text { hsa-mir-423, } \\
\text { hsa-mir-324, } \\
\text { hsa-mir-33b }\end{array}$ \\
\hline $17 q 11.2-q 12$ & 28369.71 & 29170.12 & Yes & $2(1)$ & ACCN1 & \\
\hline $17 q 12$ & 29347.57 & 29842.55 & Yes & $2(0)$ & CCL8, CCL1, CCL2, CCL11, CCL7, ACCN1, CCL13 & \\
\hline $17 q 21.33$ & 45192.43 & 45766.56 & Yes & $3(2)$ & $\begin{array}{l}\text { ITGA3, PPP1R9B, PDK2, MYST2, COL1A1, FAM117A, } \\
\text { TAC4, DLX3, TMEM92, DLX4, SAMD14, SGCA, HILS1 }\end{array}$ & \\
\hline $17 q 21.33$ & 46753.68 & 47115.08 & Yes & $3(2)$ & FLJ42842, CA10 & \\
\hline $17 q 23.2-q 23.3$ & 57237.42 & 57657.12 & Yes & $4(3)$ & THRAP1, BRIP1, INTS2 & \\
\hline $17 q 25.1$ & 69945.06 & 71453.61 & Yes & $2(2)$ & & \\
\hline
\end{tabular}


Table 3 Continued

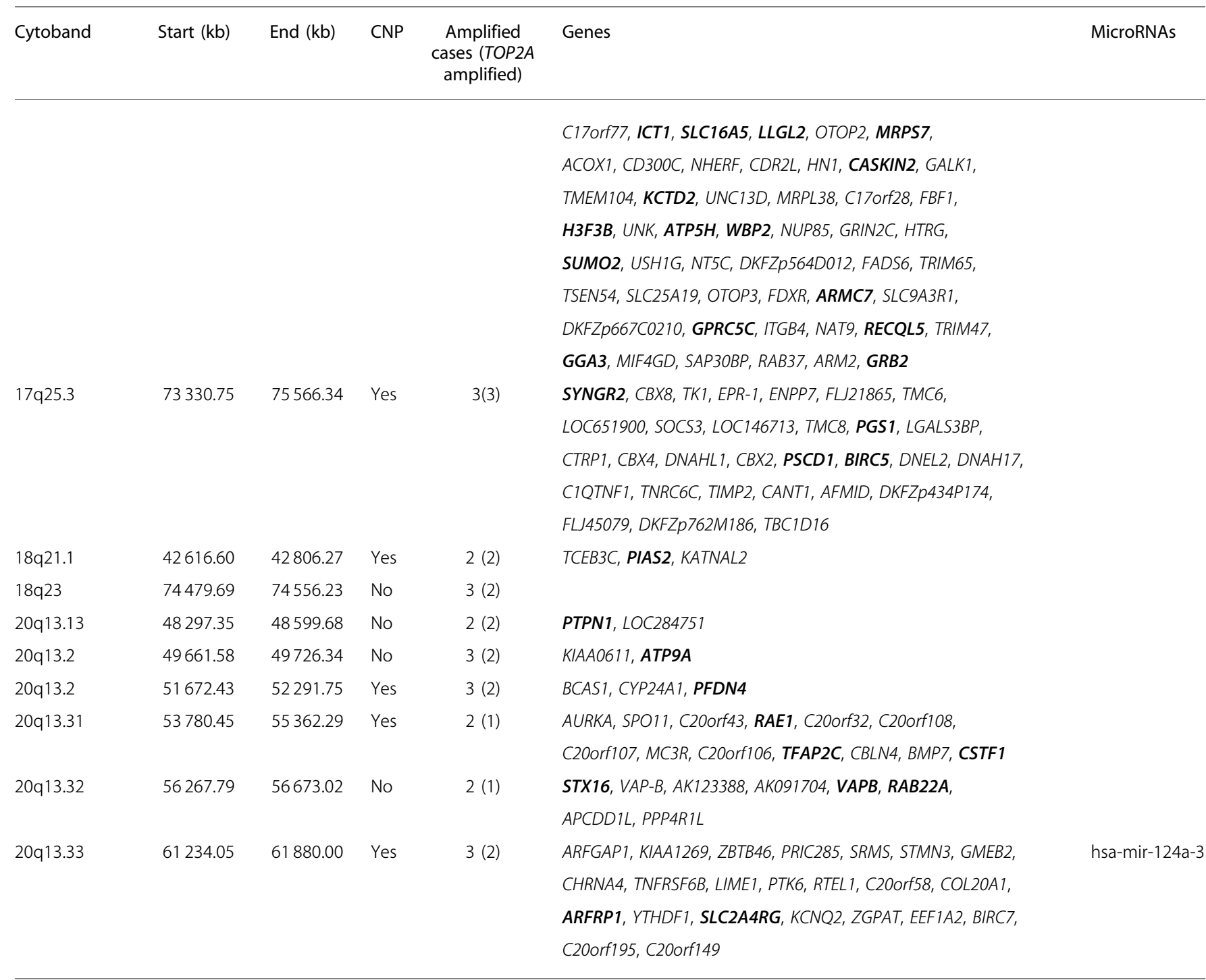

CNP, copy number polymorphism.

In bold, genes that are reported to be overexpressed when amplified. ${ }^{13,15-18,21,23}$

Analysis of the six HER2-amplified cell lines revealed that only SKBR3 and UACC812, which harbour HER2/TOP2A co-amplification, are appropriate models for HER2/TOP2Aamplified breast cancers. Furthermore, MDA-MB-361, MDAMB-453 and ZR-75.30 do not appear to be ideal in vitro models for HER2-amplified breast cancers in general, given that these cell lines have a luminal expression profile, ${ }^{18}$ are positive for ER and harbour TOP2A deletions. TOP2A gene deletions are likely to have a significant impact on the biology of HER2-amplified breast cancers and are rather infrequent in human tumours. ${ }^{37-39}$

We have also identified complex patterns of copy number changes on chromosome 17 in HER2/TOP2A-co-amplified breast cancers. Owing to the high resolution of our aCGH platform, we could define the smallest regions of recurrent deletions on $17 \mathrm{p}$ and recurrent high-level gains/amplifications either proximal or distal to but not in continuity with the HER 2 amplicon. These additional amplicons on $17 \mathrm{q}$ may harbour potential oncogenes and therapeutic targets (Table 3 ) as some of these genes are consistently overexpressed when amplified. ${ }^{18,21,24}$ For example, BIRC5 (17q25.3) encodes the apoptosis inhibitor survivin, which has been shown to correlate with lack of ER, high histological grade and a poor prognosis in breast cancer when overexpressed. ${ }^{40}$ In addition, there also appears to be a link between HER2 overexpression and aberrant regulation of survivin in breast cancer. ${ }^{41}$ There are burgeoning data to suggest that survivin may be an useful therapeutic target given that (i) survivin small-molecule inhibitors are reported to induce regression of human hormone-refractory prostate tumour xenografts ${ }^{42}$ and 
(ii) histone deacetylase inhibitors have also shown to decrease the expression of survivin and may have a role alone or in combination with the standard treatments for HER2 + tumours. ${ }^{43}$ GRB2 (17q25.1) encodes the growth factor receptor-binding protein 2 , which is an adaptor protein that binds to an autophosphorylated site within the cytoplasmic tail of the HER2 receptor. The HER2-Grb2 coupled signalling pathway has been shown to induce the development of mammary tumours with unique morphological characteristics and a high metastatic potential in transgenic mouse models. ${ }^{44}$ Inhibition of Grb2 expression using siRNA has been shown to inhibit proliferation of bcr-abl-positive leukaemia cell lines and prolong survival in mice bearing bcrabl-positive leukaemia xenografts. ${ }^{45}$ Our results suggest that further studies designed to test survivin and GRB2 as additional therapeutic targets for HER2/TOP2A-amplified breast cancers are warranted.

Additional regions of recurrent amplification are apparent in our analysis (Table 3). Although amplification of HER2 may be the best characterised genetic event in the development of these tumours, there are several genes included in these co-amplified regions that may also play a critical role in tumour development and response to therapy. For instance, the amplicon on chromosome 1q23 contains PEA15, which has a role in the development of other tumour types and interacts with the ERK/MAPK pathway, ${ }^{46}$ whereas RAB22A on 20q13.2 belongs to the well-defined RAS oncogene family, which plays a crucial role in many types of cancer. ${ }^{47}$ Although trastuzumab therapy is already changing the natural history of HER2 + breast cancer, these tumours harbour multiple additional amplifications of genes that may either explain the primary resistance of specific subgroups of HER2 + tumours to this therapy or could be tested as possible additional therapeutic targets for these tumours.

Despite the limited sample size of our study, combined $\mathrm{CISH}$ and aCGH analysis has revealed that CISH provides a reliable assessment of HER2 and TOP2A amplification. The accuracy of this technique, when compared to the results of aCGH analysis, was $100 \%$ for highly amplified cases. However, cases with low-level amplification may require correction with CEP17 probes.

In conclusion, our study provides the first detailed molecular characterisation of HER2/TOP2A-amplified breast cancer, defines the SRA on 17q12-q21 in cases harbouring HER2/TOP2A co-amplification and identifies the SKBR3 and UACC812 cell lines as in vitro models for this breast cancer subtype. Unlike basal-like cancers, these tumours less frequently display multiple low-level gains and deletions and more frequently harbour recurrent amplifications. Further studies on the genetic mechanisms behind these multiple amplifications and the recurrently amplified and overexpressed genes identified in our analysis may lead to a better understanding of this molecular subgroup of breast cancers. Most importantly, some of the genes identified in this study can be targeted by drugs in early phases of development with promising antitumoural activity. Our results pave the way for further studies testing these genes as therapeutic targets in HER2 + breast carcinomas.

Supplementary Information accompanies the paper on the Laboratory Investigation website (http://www.laboratoryinvestigation.org).

\section{ACKNOWLEDGEMENT}

This study was funded by Breakthrough Breast Cancer. Caterina Marchió is funded in part by Associazione Italiana per la Ricerca sul Cancro (AIRC, Milan, Regional Grant 1182).

\section{DISCLOSURE/DUALITY OF INTEREST}

None.

1. Jonkers J, Berns A. Oncogene addiction: sometimes a temporary slavery. Cancer Cell 2004;6:535-538.

2. Baselga J, Tripathy D, Mendelsohn J, et al. Phase II study of weekly intravenous trastuzumab (Herceptin) in patients with HER2/neuoverexpressing metastatic breast cancer. Semin Oncol 1999;26:78-83.

3. Piccart-Gebhart MJ, Procter M, Leyland-Jones B, et al. Trastuzumab after adjuvant chemotherapy in HER2-positive breast cancer. N Engl J Med 2005;353:1659-1672.

4. Romond EH, Perez EA, Bryant J, et al. Trastuzumab plus adjuvant chemotherapy for operable HER2-positive breast cancer. N Engl J Med 2005;353:1673-1684.

5. Muss HB, Thor AD, Berry DA, et al. c-erbB-2 expression and response to adjuvant therapy in women with node-positive early breast cancer. $\mathrm{N}$ Engl J Med 1994;330:1260-1266.

6. Paik S, Bryant J, Park C, et al. erbB-2 and response to doxorubicin in patients with axillary lymph node-positive, hormone receptor-negative breast cancer. J Natl Cancer Inst 1998;90:1361-1370.

7. Pritchard KI, Shepherd LE, O'Malley FP, et al. HER2 and responsiveness of breast cancer to adjuvant chemotherapy. $\mathrm{N}$ Engl J Med 2006;354:2103-2111.

8. Arriola E, Rodriguez-Pinilla SM, Lambros MB, et al. Topoisomerase II alpha amplification may predict benefit from adjuvant anthracyclines in HER2 positive early breast cancer. Breast Cancer Res Treat 2007;106:181-189.

9. Knoop AS, Knudsen H, Balslev $E$, et al. Retrospective analysis of topoisomerase Ila amplifications and deletions as predictive markers in primary breast cancer patients randomly assigned to cyclophosphamide, methotrexate, and fluorouracil or cyclophosphamide, epirubicin, and fluorouracil: Danish Breast Cancer Cooperative Group. J Clin Oncol 2005;23:7483-7490.

10. Tanner M, Isola J, Wiklund $\mathrm{T}$, et al. Topoisomerase Ilalpha gene amplification predicts favorable treatment response to tailored and dose-escalated anthracycline-based adjuvant chemotherapy in HER-2/ neu-amplified breast cancer: Scandinavian Breast Group Trial 9401. J Clin Oncol 2006;24:2428-2436.

11. Arriola E, Moreno A, Varela M, et al. Predictive value of HER-2 and topoisomerase llalpha in response to primary doxorubicin in breast cancer. Eur J Cancer 2006;42:2954-2960.

12. Jarvinen TA, Tanner M, Barlund $M$, et al. Characterization of topoisomerase II alpha gene amplification and deletion in breast cancer. Genes Chromosomes Cancer 1999;26:142-150.

13. Di Leo A, Gancberg D, Larsimont D, et al. HER-2 amplification and topoisomerase Ilalpha gene aberrations as predictive markers in nodepositive breast cancer patients randomly treated either with an anthracycline-based therapy or with cyclophosphamide, methotrexate, and 5-fluorouracil. Clin Cancer Res 2002;8:1107-1116.

14. Kauraniemi $\mathrm{P}$, Barlund $\mathrm{M}$, Monni $\mathrm{O}$, et al. New amplified and highly expressed genes discovered in the ERBB2 amplicon in breast cancer by cDNA microarrays. Cancer Res 2001;61:8235-8240.

15. Kauraniemi $P$, Kuukasjarvi T, Sauter $G$, et al. Amplification of a 280-kilobase core region at the ERBB2 locus leads to activation of two hypothetical proteins in breast cancer. Am J Pathol 2003;163: 1979-1984.

16. Jarvinen TA, Tanner M, Rantanen V, et al. Amplification and deletion of topoisomerase Ilalpha associate with ErbB-2 amplification and affect 
sensitivity to topoisomerase II inhibitor doxorubicin in breast cancer. Am J Pathol 2000;156:839-847.

17. Orsetti B, Nugoli $M$, Cervera N, et al. Genomic and expression profiling of chromosome 17 in breast cancer reveals complex patterns of alterations and novel candidate genes. Cancer Res 2004;64:6453-6460.

18. Neve RM, Chin K, Fridlyand J, et al. A collection of breast cancer cell lines for the study of functionally distinct cancer subtypes. Cancer Cell 2006;10:515-527.

19. Reis-Filho JS, Simpson PT, Jones C, et al. Pleomorphic lobular carcinoma of the breast: role of comprehensive molecular pathology in characterization of an entity. J Pathol 2005;207:1-13.

20. van Beers $\mathrm{EH}$, Joosse SA, Ligtenberg MJ, et al. A multiplex PCR predictor for aCGH success of FFPE samples. Br J Cancer 2006;94: 333-337.

21. Chin K, DeVries S, Fridlyand J, et al. Genomic and transcriptional aberrations linked to breast cancer pathophysiologies. Cancer Cell 2006;10:529-541.

22. Arriola $E$, Lambros MB, Jones $C$, et al. Evaluation of Phi29-based wholegenome amplification for microarray-based comparative genomic hybridisation. Lab Invest 2007;87:75-83.

23. Bustin SA. Absolute quantification of mRNA using real-time reverse transcription polymerase chain reaction assays. J Mol Endocrinol 2000;25:169-193.

24. Hicks J, Krasnitz A, Lakshmi B, et al. Novel patterns of genome rearrangement and their association with survival in breast cancer. Genome Res 2006;16:1465-1479.

25. Chin SF, Wang Y, Thorne NP, et al. Using array-comparative genomic hybridization to define molecular portraits of primary breast cancers. Oncogene 2007;26:1959-1970.

26. Wolff AC, Hammond ME, Schwartz JN, et al. American Society of Clinical Oncology/College of American Pathologists guideline recommendations for human epidermal growth factor receptor 2 testing in breast cancer. J Clin Oncol 2007;25:118-145.

27. Redon R, Ishikawa S, Fitch KR, et al. Global variation in copy number in the human genome. Nature 2006;444:444-454.

28. Wong KK, deLeeuw RJ, Dosanjh NS, et al. A comprehensive analysis of common copy-number variations in the human genome. Am J Hum Genet 2007;80:91-104.

29. Simpson PT, Reis-Filho JS, Gale T, et al. Molecular evolution of breast cancer. J Pathol 2005;205:248-254.

30. Buerger $H$, Mommers EC, Littmann $R$, et al. Ductal invasive $G 2$ and $G 3$ carcinomas of the breast are the end stages of at least two different lines of genetic evolution. J Pathol 2001;194:165-170.

31. Kao J, Pollack JR. RNA interference-based functional dissection of the $17 q 12$ amplicon in breast cancer reveals contribution of coamplified genes. Genes Chromosomes Cancer 2006;45:761-769.

32. Pero SC, Shukla GS, Cookson MM, et al. Combination treatment with Grb7 peptide and doxorubicin or trastuzumab (Herceptin) results in cooperative cell growth inhibition in breast cancer cells. Br J Cancer 2007;96:1520-1525.
33. Degot $\mathrm{S}$, Regnier $\mathrm{CH}$, Wendling $\mathrm{C}$, et al. Metastatic lymph node 51, a novel nucleo-cytoplasmic protein overexpressed in breast cancer. Oncogene 2002;21:4422-4434.

34. Troxell ML, Bangs CD, Lawce HJ, et al. Evaluation of Her-2/neu status in carcinomas with amplified chromosome 17 centromere locus. Am J Clin Pathol 2006;126:709-716.

35. Garcia-Pedrero JM, Kiskinis E, Parker MG, et al. The SWI/SNF chromatin remodeling subunit BAF57 is a critical regulator of estrogen receptor function in breast cancer cells. J Biol Chem 2006;281:22656-22664.

36. Gonzalez S, Klatt $\mathrm{P}$, Delgado $\mathrm{S}$, et al. Oncogenic activity of Cdc6 through repression of the INK4/ARF locus. Nature 2006;440: 702-706.

37. Bouchalova $\mathrm{K}$, Trojanec $\mathrm{R}$, Kolar $\mathrm{Z}$, et al. Analysis of ERBB2 and TOP2A gene status using fluorescence in situ hybridization versus immunohistochemistry in localized breast cancer. Neoplasma 2006:53:393-401.

38. Park K, Han S, Gwak GH, et al. Topoisomerase II-alpha gene deletion is not frequent as its amplification in breast cancer. Breast Cancer Res Treat 2006;98:337-342.

39. Hicks DG, Yoder BJ, Pettay J, et al. The incidence of topoisomerase IIalpha genomic alterations in adenocarcinoma of the breast and their relationship to human epidermal growth factor receptor- 2 gene amplification: a fluorescence in situ hybridization study. Hum Pathol 2005;36:348-356.

40. Hinnis AR, Luckett JC, Walker RA. Survivin is an independent predictor of short-term survival in poor prognostic breast cancer patients. $\mathrm{Br} \mathrm{J}$ Cancer 2007;96:639-645.

41. Xia W, Bisi J, Strum J, et al. Regulation of survivin by ErbB2 signaling: therapeutic implications for ErbB2-overexpressing breast cancers. Cancer Res 2006;66:1640-1647.

42. Nakahara T, Takeuchi M, Kinoyama I, et al. YM155, a novel smallmolecule survivin suppressant, induces regression of established human hormone-refractory prostate tumor xenografts. Cancer Res 2007;67:8014-8021.

43. Bevins RL, Zimmer SG. It's about time: scheduling alters effect of histone deacetylase inhibitors on camptothecin-treated cells. Cancer Res 2005;65:6957-6966.

44. Schade B, Lam SH, Cernea D, et al. Distinct ErbB-2 coupled signaling pathways promote mammary tumors with unique pathologic and transcriptional profiles. Cancer Res 2007;67:7579-7588.

45. Tari AM, Gutierrez-Puente Y, Monaco G, et al. Liposome-incorporated Grb2 antisense oligodeoxynucleotide increases the survival of mice bearing bcr-abl-positive leukemia xenografts. Int J Oncol 2007;31:1243-1250.

46. Renganathan $\mathrm{H}$, Vaidyanathan $\mathrm{H}$, Knapinska $\mathrm{A}$, et al. Phosphorylation of PEA-15 switches its binding specificity from ERK/MAPK to FADD. Biochem J 2005;390:729-735.

47. Kauppi M, Simonsen A, Bremnes B, et al. The small GTPase Rab22 interacts with EEA1 and controls endosomal membrane trafficking. J Cell Sci 2002;115:899-911. 